\title{
The Problems and Countermeasures Faced in the Process of Implementation of "Jin Mo brownouts" Policy
}

\author{
Zhenyu Fan \\ North China Electric Power University (Baoding), Baoding, 071000, China \\ email:1003474817@qq.com
}

Keywords:"Jin Mo brownouts", Mathematical modeling, Logit model, Countermeasures

\begin{abstract}
In order to make the policy "Jin Mo brownouts" supported by the majority, it is necessary to demonstrate it without ideology of science. This paper builds a mathematical model, makes a quantitative analysis of "Jin Mo brownouts" policy in the implementation of the problems facing and analyzes the causes of the problems and the countermeasures, basing on the factors such as the total amount of traffic resources in a city, namely the traffic capacity of the road, the structure of the traffic demand, the efficiency of various vehicles and the influence on the safety and the environment.
\end{abstract}

\section{Introduction}

From the beginning of March 21st, the most stringent "Jin Mo brownouts" focus on the action carried out in Shenzhen. The focus of the action in the subway, bus stations, ports and commercial areas, such as illegal soliciting illegal collection [1-3]. According to the city traffic police bureau informed the actions carried out within 10 days, a total of 17975 electric vehicles seized, detained 874 people [4].

Different from the previous time is short, small regional restrictions, the Jin Mo brownouts lasted 100 days (from March to the end of June), the scope of regulation includes the key area, gathering area for the subway, bus stations, ports, bustling commercial area. And the key areas are touting showmanship, administrative detention. Since April 1st, the illegal use of electric (motor) tricycle all administrative detention [5].

\section{We take Chaohu as an example to establish the model}

According to the survey data of travel data, the residents used to analyze the main way to travel, bicycles, electric cars, public transport and car 4. The sample size and proportion of the 4 travel modes are shown in Table 1 . Table 1 shows that the old Chaohu city residents choose electric car travel proportion is $28.2 \%$, the proportion is highest in 4 ways; second car ratio $24.3 \%$; bicycles and public transport travel is not very different, respectively $20.9 \%$ and $16.5 \%$..

Table 1 The sample size and proportion of the 4 travel modes

\begin{tabular}{c|c|c}
\hline Travel mode & Sample size & Percent\% \\
\hline Bicycle & 258 & 20.9 \\
\hline Electric vehicle & 472 & 28.2 \\
\hline Public transportation & 201 & 16.5 \\
\hline Car & 300 & 24.3 \\
\hline Total & 1232 & 100 \\
\hline
\end{tabular}

\section{The Application of Logit Model in Urban Traffic Sharing}

The range of application of the multinomial Logit model is that the dependent variable is unordered type variable, which is suitable for 3 kinds and more than 3 dependent variables. In this study, the travel mode choice of the old city, the dependent variables for the 4 modes of travel, in line with the 
requirements of a number of Logit modeling. Based on the random utility theory, the individual choice of the in travel model " $U_{\text {in }}$ " can be expressed as: type in " $V_{\text {in }}$ " for the $N$ individual choice of the I travel mode fixed in the utility function; " $\varepsilon_{\text {in }}$ " for the $n$ of the I individuals choose the random utility model activities in the function. When there is a linear relationship between " $V_{\text {in }}$ " and the explanatory variables contained therein, it can be expressed as:

$$
V_{i n}=\theta^{\prime} X_{i n}=\sum_{k-1}^{k} \theta_{k} x_{i n k}
$$

In the formula: The " $K$ " is the number of explanatory variables; the parameter matrix; The " $\theta$ " is the corresponding parameter of the first $k$ variables; The " $x_{i n k}$ " for the first $n$ individuals to select the first I activity patterns of the K variable.

Assuming that the random items in the utility function obey the double exponential distribution, we can get the probability that the first $\mathrm{n}$ individuals choose I activity patterns.

$$
P_{i n}=\frac{\exp V_{i n}}{\sum_{j \in A_{n}} \exp V_{j n}}=\frac{\exp \left(\sum_{k=1}^{k} \theta_{k} x_{i n k}\right)}{\sum_{j \in A_{n}} \exp \left(\sum_{k=1}^{k} \theta_{k} x_{j n k}\right)}
$$

In the formula: the " $V_{\text {in }}$ " is the first $n$ individuals to choose the I and $\mathrm{K}$ travel mode utility function of the fixed term; The " $x_{\text {ink }}$ " for the first $n$ individuals to select the first $\mathrm{J}$ activity patterns of the first variable. The type (3) deformation, and the maximum likelihood estimation method and Newton Rappsson solution, we can estimate the parameters in model, $\theta_{1}, \theta_{2} \ldots \theta_{k}$.

\section{Model Results and Analysis}

Using statistical analysis software SPSS multinational regression logistic module, the commuter travel mode choice model. Travel mode is divided into bicycles, electric cars, public transport and cars. The explanatory variables are the individual characteristics, family characteristics and trip characteristics of commuters. The classification and value of each explanatory variable are shown in Table 2.

PSS set the $0-1$ variable at runtime by setting the $\mathrm{J}$ class variable to $\mathrm{J}-1$ two - value dummy variables, and automatically refer to the last class of the variables as the reference category. The results of this paper are shown in Table 3. As can be seen from Table 3. The relationship between commuter travel patterns, personal characteristics, family characteristics and trip characteristics in the old city is as follows:

The values of Men in the bicycle, electric vehicles and public transport calibration were -1.891 , $-2.126,-1.802$, which were negative, indicating that the male choice of these 3 modes of travel probability lower than women.

The Results of the Calibration of Occupational Variable Workers in Electric Vehicles are 0.24, which Shows that the Workers Tend to Choose Electric Vehicles as a Daily Commuter. The results of a bicycle with a population of less than 40 years of age are positive, indicating that the probability of such a walker's choice of a bicycle is greater.

Under the way of bicycle, the test results of family without electric car are positive, which is more inclined to choose bicycles. Family without electric cars in the electric vehicle estimates for the negative -1.75 , indicates that the family would not choose electric car travel, which is consistent with the actual situation. Family without car in the calibration of public transportation value is 2.751, indicating that the probability of public transport is greater for families without cars. 
Table 2 classification and value of explanatory variables

\begin{tabular}{|c|c|c|c|}
\hline \multicolumn{2}{|c|}{ Variable } & Variable value & Variable description \\
\hline \multirow{13}{*}{$\begin{array}{c}\text { Personal } \\
\text { characteristics }\end{array}$} & \multirow{2}{*}{ Gender } & 1 & Male \\
\hline & & 2 & Female \\
\hline & \multirow{3}{*}{ Occupation } & 1 & Worker \\
\hline & & 2 & Civil servant \\
\hline & & 3 & Private \\
\hline & \multirow{2}{*}{ Age } & 1 & At the age of $<40$ \\
\hline & & 2 & $>=40$ years \\
\hline & \multirow{2}{*}{ Family population } & 1 & $<3$ \\
\hline & & 2 & $>=3$ \\
\hline & \multirow{2}{*}{ Preschool children } & 1 & Yes \\
\hline & & 0 & No \\
\hline & \multirow{2}{*}{ Household income } & 1 & $<3$ \\
\hline & & 2 & $>=3$ \\
\hline \multirow{8}{*}{$\begin{array}{c}\text { Family } \\
\text { characteristics }\end{array}$} & \multirow{2}{*}{ Bicycle } & 0 & No \\
\hline & & 1 & Yes \\
\hline & \multirow{2}{*}{ Electric vehicle } & 0 & No \\
\hline & & 1 & Yes \\
\hline & \multirow{2}{*}{ A car } & 0 & No \\
\hline & & 1 & Yes \\
\hline & \multirow{2}{*}{ Early peak travel } & 0 & No \\
\hline & & 1 & Yes \\
\hline \multirow{4}{*}{$\begin{array}{c}\text { Trip } \\
\text { characteristics }\end{array}$} & \multirow{2}{*}{ Late peak travel } & 0 & No \\
\hline & & 1 & Yes \\
\hline & \multirow{2}{*}{ Travel time } & 1 & $<=20$ \\
\hline & & 2 & $>30$ \\
\hline
\end{tabular}

Table 3 Model results

\begin{tabular}{|c|c|c|c|c|c|c|}
\hline \multirow[t]{2}{*}{ Variable } & Bicycle & & $\begin{array}{l}\text { Electric } \\
\text { vehicle }\end{array}$ & & $\begin{array}{c}\text { Public } \\
\text { transportation }\end{array}$ & \\
\hline & Coefficient & value of $\mathrm{P}$ & Coefficient & value of $\mathrm{P}$ & Coefficient & value of $\mathrm{P}$ \\
\hline Constant term & & & 1.242 & 0.012 & & \\
\hline Male & -1.891 & 0 & -2.126 & 0 & -1.802 & 0 \\
\hline Worker & & & 0.24 & 0.033 & & \\
\hline \multicolumn{7}{|l|}{ Civil servant } \\
\hline Age $<40$ years & 0.501 & 0.043 & & & & \\
\hline \multicolumn{2}{|c|}{ Family population $<=3$} & & & & -0.933 & 0.025 \\
\hline \multicolumn{2}{|c|}{ Household income $<3$ million } & & 0.376 & 0.01 & & \\
\hline No electric car & \begin{tabular}{l|l|} 
& 0.469 \\
\end{tabular} & 0.039 & -1.75 & 0 & & \\
\hline No car & 3.422 & 0 & & & 2.751 & 0 \\
\hline No bike & \begin{tabular}{l|r|} 
& -1.612 \\
\end{tabular} & 0 & & & -1.035 & 0.024 \\
\hline \multicolumn{2}{|c|}{ Not in the early peak travel } & & 1.396 & 0.002 & & \\
\hline \multicolumn{7}{|c|}{ Not in the late peak travel } \\
\hline \multicolumn{2}{|c|}{ Travel time $<20 \mathrm{~min}$} & & 0.033 & 0.02 & -1.517 & 0.001 \\
\hline
\end{tabular}

Note: the car as a reference category; blank indicates that the results are not significant. 


\section{Through the Research of the Model, the Countermeasures are Put Forward}

Through the model of "Jin Mo brownouts" policy analysis, the policy has a strong scientific, implementation to alleviate traffic pressure and reduce traffic accidents. However, the current electric cars and motorcycles with a number of features such as the use of a wide range, the implementation of the policy will be subject to certain obstacles. The implementation of the policy will aim to serve the people. So, we established the Logit model of the "Jin Mo brownouts" policy analyzed it and put forward some suggestions on the basis of the analysis.

Ectric vehicles and motorcycles banned and prohibited can be distributed to avoid taking a one size fits all approach. The government should rent the scientific and democratic decision-making, get rid of the public transportation, rental, parking fees, the introduction of competition mechanism. The principle of public transport priority, the establishment of fast, environmentally friendly, low-cost public transport system, so that people improve travel efficiency, and gradually reduce the use of motorcycles electric cars and cars.

Electric cars should be listed. Strengthen the management of motorcycles and electric vehicles.

The implementation of the policy between Jin Mo brownouts must strengthen departmental and executive departments, between the actuator system, between the policy implementation institutions and policy target group communication. In publicity, "Jin Mo brownouts" should be a process, rather than Every order is executed without fail. Electric cars and motorcycles from the production to the demise of the law, the implementation of the policy is based on the success of the publicity work. Let the ordinary people understand the policy, rather than "three tiger" distorted policy implications.

\section{Conclusion}

Through the establishment and analysis of the model, it can be found that due to the characteristics of urban land use, as well as the characteristics of the residents in the region, residents are more inclined to choose electric vehicles. But with the popularity of electric vehicles, electric vehicles often travel as a primary consideration, which will become the need to be solved in the implementation of "Jin Mo brownouts" policy.

\section{References}

[1] Lu Lin, Chen Xuewu. The analysis of the impact of the "limited liability" policy on urban traffic in Changzhou city.2005 ([J].) (03)

[2] Zhao Zhihong, Xiang Qiao Jun, Wang Wei, et al. Analysis of the influence of motorcycle on urban traffic [J]. transportation system engineering and information.2005 (01)

[3] Wang Zhenqun. Research on the problems and solutions of Foshan motorcycle traffic [J]. transportation system engineering and information.2003 (01)

Journal of Wuhan University of Technology, Vol. second, April 2010, thirty-fourth

[4] limits of motor vehicles, the limitation of property rights and the principle of proportionality [J]. Zhang Xiang. Law. 2015 (02)

[5] "Jin Mo brownouts rationality analysis", Dai Li, Wang Zijie, intelligent management,2017(01) 